\title{
RETHINKING CONSERVATION
}

\section{TOWARDS A PARADIGM SHIFT}

\author{
ALEJANDRO MARTÍNEZ-ABRAÍN
}

\begin{abstract}
Between the mid-1980s and the present day, conservation biology split into two almost independent fields: management ecology and conservation ecology. We have witnessed the recovery of large endangered species and a decrease in small and common species. In addition, the abandonment of rural areas has allowed the expansion of forest species and has hurt those that inhabit open spaces and who are linked to traditional farming. Many species that once lived only in refuges are now starting to venture further out and are losing their fear of humans. Moreover, environments that have become anthropic are now being successfully occupied more often. In short, we are going towards a world that reconciles humans and wildlife, which will be beneficial, but will also pose new challenges.
\end{abstract}

Keywords: land abandonment, conservation biology, endangered species, reconciliation ecology.

In the mid-1980s, conservation biology was born, thanks to Michael Soulé, as a discipline to tackle the biodiversity crisis (Soulé, 1986). Over time, it has split into two tangential fields. On the one hand, ecologists are doing ecological science research and trying to include humans among the spectrum of factors that can influence population dynamics or the structure of communities (e.g., Forester \& Machlist, 1996); their ultimate goal is to understand more about the biosphere. On the other hand, public administrations, NGOs, and private foundations do conservation work to reach specific objectives, whether it is to favour a specific ecosystem, to improve the demographic status of endangered species, or to recover species that were lost at the local or regional scale. The practitioners of both types of conservation tend to blame each other for their scarce interaction. Ecologists feel ignored by managers, and the latter feel that ecologists live in their «ivory towers».

However, because the two disciplines have drifted apart so much that they are currently almost independent from each other, one might think that this is not a problem at all. In certain ways, ecologists who include the human factor in their studies can inform those responsible for conservation decisionmaking, but their opinion is but one more suggestion among the many put forward to these administrators. Social and political aspects often carry more weight - understandably so, because environmental administration is carried out by and for people, rather than for the development of knowledge. That latter goal depends on other departments.

The fact that this dichotomy has not yet been incorporated into management means that many social or economic problems become camouflaged as biological issues. So-called invasive species are a good example of this. For example, let us consider the current large-scale parrot cullings now occurring in several Spanish cities (some completed, some still underway). Although there is barely any evidence that these parrots have a negative effect on other animal species, their removal has been justified with biology. However, this masks the fact that the largest point of friction between parrots and humans is the former's potential to damage crops (Postigo, 2017). We are unaware of rose-ringed parakeets (Psittacula krameri) having caused any documented ecological damage to third parties, and the only argument used 


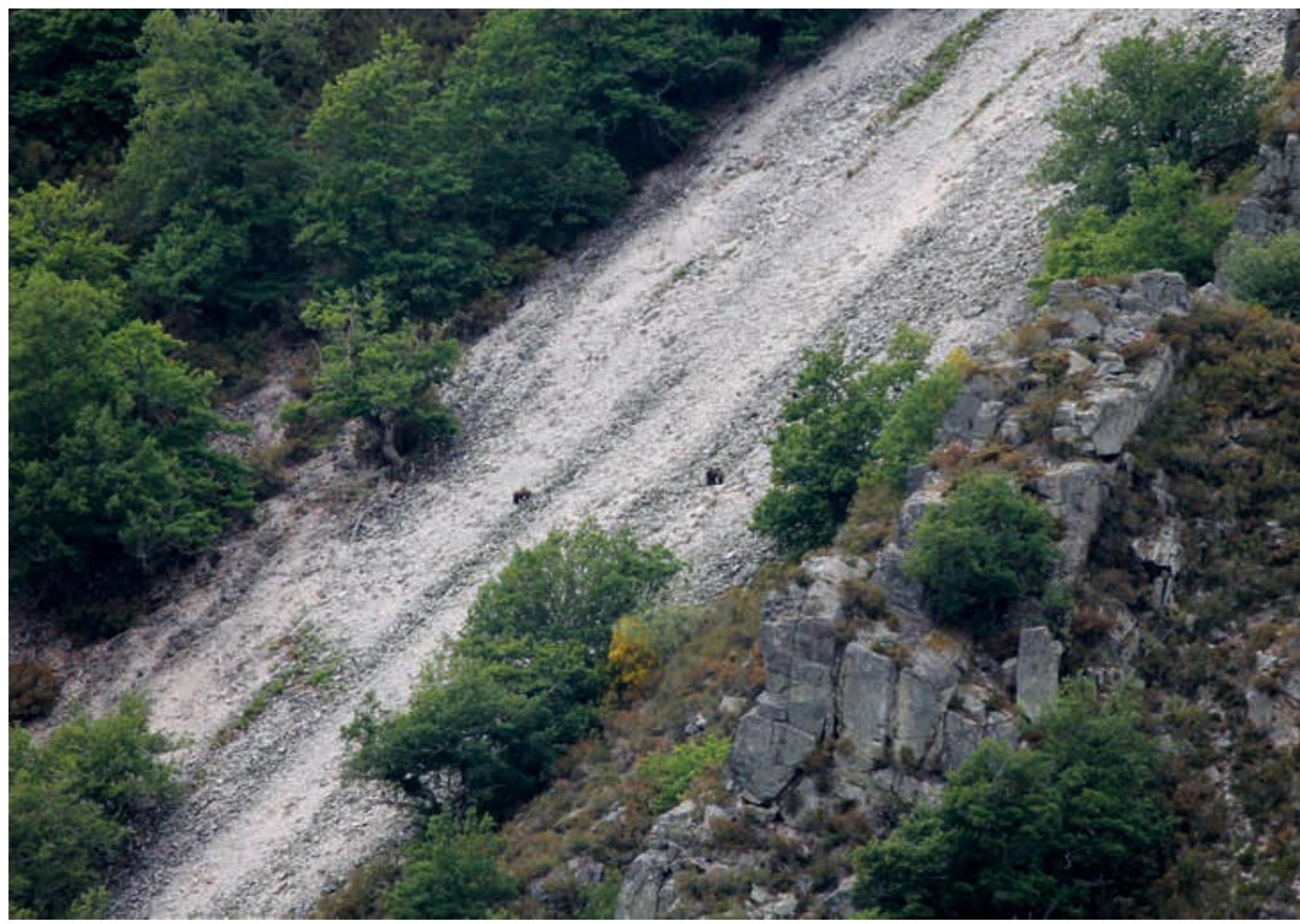

against monk parakeets (Myiopsitta monachus) is that they displace two other species - even though these species themselves actually breed in completely artificial anthropic environments: greater noctule bats (Nyctalus lasiopterus) take refuge in exotic palm trees in an urban park in Seville, and lesser kestrels (Falco naumanni) breed in building cavities (op. cit.). In both cases, the problem is of a technical nature: we could provide appropriate nesting boxes for bats or build structures for kestrels on building rooftops so that the availability of appropriate spaces for these animals ceased to be a limiting factor. The time for removing parrots as a precautionary measure passed when they stopped being rare in our cities. Therefore, biology does not justify these cullings. In addition, as often happens with many newly arriving species, present predators such as peregrine falcons or booted eagles (García, 2018) already had a search image of parrots as prey, so the abundance of these parrots is also expected to decrease when their predators increasingly start to appear in urban areas.
Figure 1. Two grizzly bears crossing a scree in the Cantabrian Mountains (Spain). Large species, which were under threat only a few years ago, are now recovering after years of intense conservation and because of the abandonment of rural areas.

"IF WE HAVE LEARNED ANYTHING

FROM STUDYING NATURE FOR 35 YEARS, IT IS THAT NATURE IS NOT VULNERABLE AND FRAGILE, BUT TOUGH AND

\section{RESILIENT»}




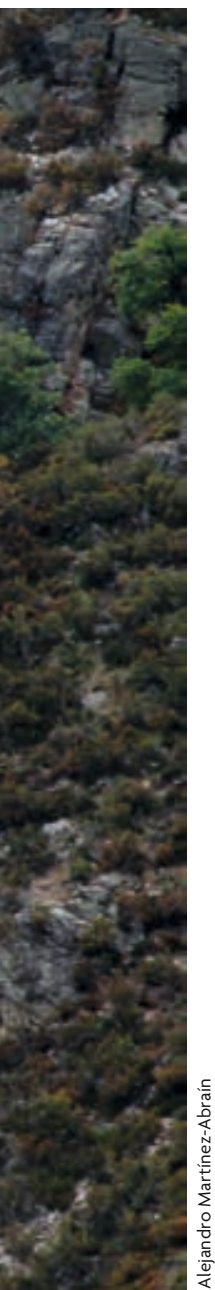

The same thing happened many years ago with yellow-legged gulls (Larus michahellis). These were considered to be a native invasive species, when in reality the problem they represented was often merely social: taking the form of attacks on tourists who wandered into breeding colonies, noise, excrements on expensive boats, or annoyance in school courtyards, among others. The biological problems caused by seagulls (such as predation or the displacement of other species) can be solved by a very different from of massive culling: i.e., the selective culling of specialist individuals, as proved in the seagull-petrel conflict on Benidorm island in Alicante, Spain (Sanz, Martínez-Abraín, Tavecchia, Mínguez, \& Oro, 2009). Moreover, the entire problem ended almost immediately when the large open-air garbage dumps that were boosting seagulls' invasive dynamic were closed down (Steigerwald, Igual, Payo-Payo, \& Tavecchia, 2015). This change probably would have been even more apparent if trawling refuse had also been avoided.

Because of this confusion between conservation ecology and conservationist management, some of the practitioners who have worked the longest in conservation science are seriously considering abandoning this discipline because they no longer feel scientifically motivated. This process will probably accelerate in the future, and the gap between the two fields is likely to grow larger. Although that is not necessarily bad; rather, scientists and administrators have simply become independent from each other. The interaction will continue to some extent, at a baseline level - not unlike the minimum services provided during a public work strike - and depending on rather personal questions: each individual decision-maker's level of appreciation for science.

On the other hand, there are no scientific rulebooks to tell us which fauna and flora should inhabit a particular location at a given time. If anything is true, it is that everything in the biosphere is dynamic and ecosystems change over time. Therefore, our desired fauna and flora are a purely human preference, and environmental administrators (as delegates of society) are responsible for making that decision. Scientists will be able to report that a focal species existed in a specific location during a given period or inform us about how a particular population will react to one type of management or another, but not much else. Resurrecting a species or leaving it in oblivion is a decision for the environmental authorities. Let us offer an example from Valencia (Spain). According to science, La Albufera in Valencia has been a coastal saltwater lagoon for most of its history. The lagoon the authorities have been trying to recover over the last few decades is the one from the most recent centuries. This is the one from after the diversion of fresh water from the river Júcar into the Antella dam (the Royal Júcar Canal) turned the water from brackish to fresh and boosted the fresh water animal and plant communities, as well as rice cultivation, in the birthplace of the world-famous Valencian paella. No scientist would recommend the environmental authorities try to revert the Albufera to its original state; the socio-economic weight behind it from the last 300 years is too powerful.

\section{THE CHANGING PARADIGM}

Be that as it may, with the help of environmental administrators, conservation scientists (or, most likely, the interaction between them both), the state of nature on the twenty-first century Iberian peninsula is very different from that of the 1980s when this type of management first started. This advance has also occurred at the same time that some power has been devolved from central government to different autonomous regions. Indeed, things have changed for the better, although mindsets anchored in the alarmist and pessimistic message of the past - although necessary at the time - still abound. To be fair, we must recognise that the evolution of Spanish society has unwittingly contributed to the success of conservation efforts, especially the almost complete abandonment of rural areas and the gathering of people in a few large cities. In addition, our civilisation's growing awareness of long-term sustainability has resulted in the implementation of exemplary environmental legislation.

Sixty years after the abandonment of the traditional subsistence farming system, most agricultural land has been reclaimed by forests and so these are good times for forest species but bad ones for species who live in open areas. Interestingly, the body-size patterns of less-favoured species have also inverted. Where once bears, wolves, lynxes, eagles, and vultures tended to decline, today these large 
species are recovering at a good pace (we already have around 300 bears, 500 lynxes, 2,000 wolves, and 500 pairs of imperial eagles, whereas in the 1980s they were all close to extinction). Meanwhile, small species such as sparrows and larks are not doing as well (Inger et al., 2014; Figure 1). This is often due to changes in habitat use, but there may also be an as yet undescribed rule of thumb that the smallest species in each taxonomic «series» may be adversely affected. In other words, small owls and scops owls, among other nocturnal birds of prey (as opposed to eagle-owls); European minks and ferrets (as opposed to otters) among mustelids; plovers among the waders; little terns among the Laridae; little bustards, as opposed to great bustards; quails among gallinaceous birds; and turtle doves as opposed to the common wood pigeon. This pattern might be due to interspecific competition by interference between species in the same group when communities are being structured, or to differential predation of the smallest species after the recovery of mesopredators (medium-sized carnivores). The practical conclusion is that, because of the laws of thermodynamics, in the words of Daniel Oro, we cannot have «a lot of everything» at the same time.

To be more precise, we should say that not all forest species have benefited from changing paradigms. One example is the capercaillie of the Pyrenees; the increase in forest surface has also increased its density and this has probably reduced the visibility that capercaillies, which breed on the ground, have against predators.

This is especially relevant now that mesopredators are recovering quickly, both because they are no longer persecuted by humans and the scarcity of apex predators to regulate them. Capercaillie hatchlings in the Pyrenees are particularly affected, so reproduction is low in spite of the high fecundity of the species, which explains how, despite all the conservation efforts, the capercaillie are still declining by $4 \%$ a year in this area (FernándezOlalla et al., 2012).

With all of this we have learned that discussing trends in conservation is very complicated because the present decline in many species is often the result of a past population explosion caused by humans. A good example of this are steppe birds; plateaus were spontaneously populated by the vegetative cover of holm oaks. Humans opened these areas and favoured the expansion of sandgrouse and great and little

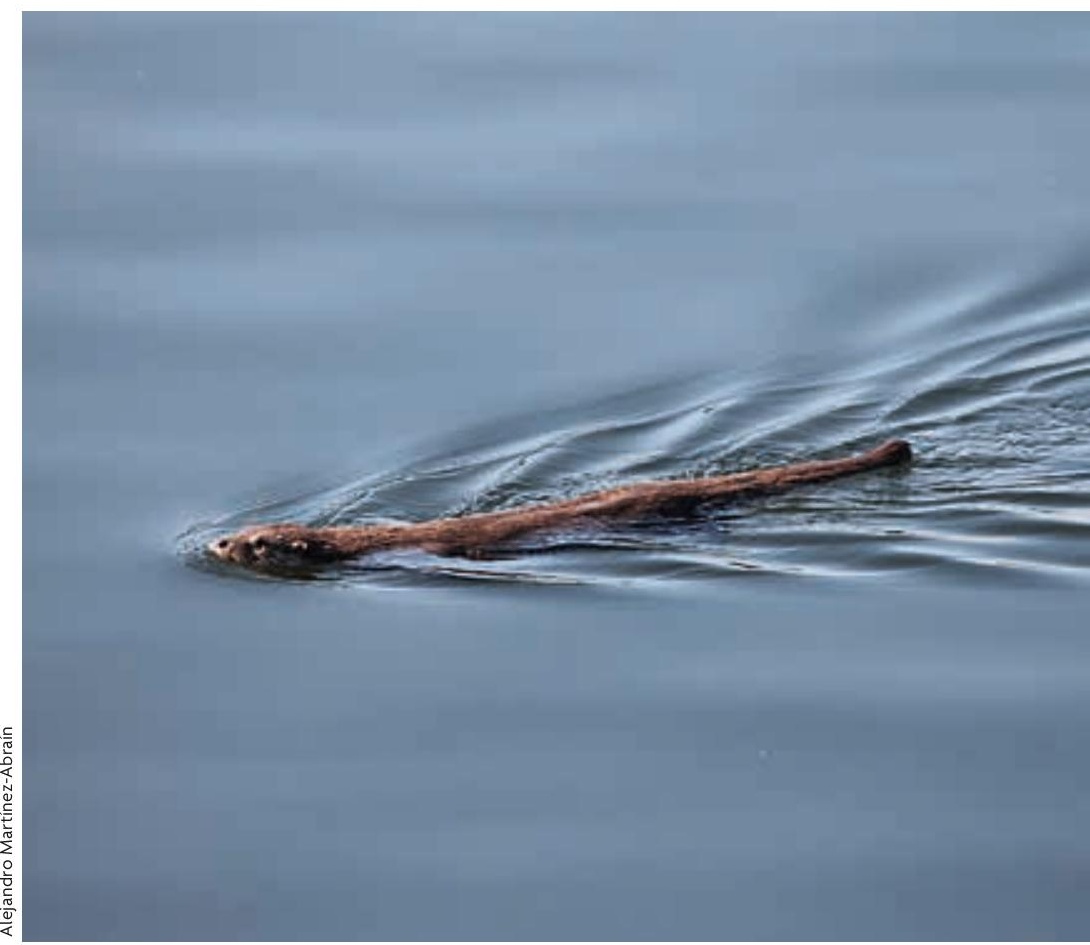

Figure 2. Until recently, otters were considered specialists from higher river stretches. Over time we have seen that, in fact, they were taking refuge in those areas because of human persecution and pollution of the medium and lower river stretches.

bustards to numbers that are now unimaginable. Their current decline is mainly an indication of a change in habitat use, whether because of the abandonment of generalised agriculture or the more intensive use of the remaining agriculture which has changed the previous mosaic-

like quality of the landscape. For example, the fallow lands that were fundamental to traditional agriculture have become meaningless now that farmers can use chemical fertilisers. Artificially maintaining the past status quo would require an unacceptable economic and energy input. But what conservation must do is ensure that the species that are currently in decline maintain sufficiently-large populations to allow them to rebound should things change again.

\section{REFUGES AND THEIR ABANDONMENT}

This directly leads me to talk about refuges. We have grown up with the idea that nature is vulnerable and fragile. However, if we have learned anything from studying nature for 35 years, it is that this idea is not true. Nature is tough and resilient and it cannot be 


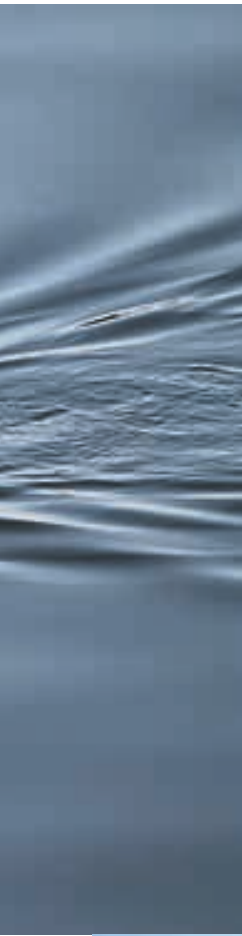

otherwise. If we think of passerine birds, the current species are a product of the evolution that kept them on this planet for at least three million years - and even longer for non-passerines.

During that time, they have had to overcome many obstacles, especially ones related to climate. When species are impacted by climate or human factors, they end up surviving in refuge areas (climate or ecological refuges), whether due to active displacement or to selective sweeping where only the populations in remote and protected locations survive. The image of nature that we began to discover in Spain in the mid1980s has turned out to be largely an artefact of the human impact. The documentaries by Félix Rodríguez de la Fuente aired in the 70s and early 80 s, which targeted the neo-urban audience who had just abandoned rural life, as well as their urbanised children, are difficult to forget. They presented otters (and other species such as the white-throated dipper or the Pyrenean desman) as specialist inhabitants from the pristine and untainted higher-river stretches. However, time has proved that otters were there not because they were specialists, but because they were in their refuges and did not have any other option. They were hunted for their skin and the middle and lower courses of rivers were contaminated. Now that both these situations have stopped or considerably improved, otters have spread all along Spanish rivers, they have occupied artificial dams and golf-course ponds, they eat exotic species, and have colonised marine and coastal areas (Figure 2).

What we are saying about otters could be said about many other predator or prey species. For decades, we thought that the Audouin's gulls (Ichthyaetus audouinii) at the Columbretes Islands in Castellón (Spain) were specialists from small rocky Mediterranean islets (Figure 3). Rather than a beetle or an endemic plant, the emblem of the Columbretes Nature Reserve is the Audouin's gull, yet these seagulls were merely refugees there (MartínezAbraín \& Jiménez, 2016). As soon as appropriate

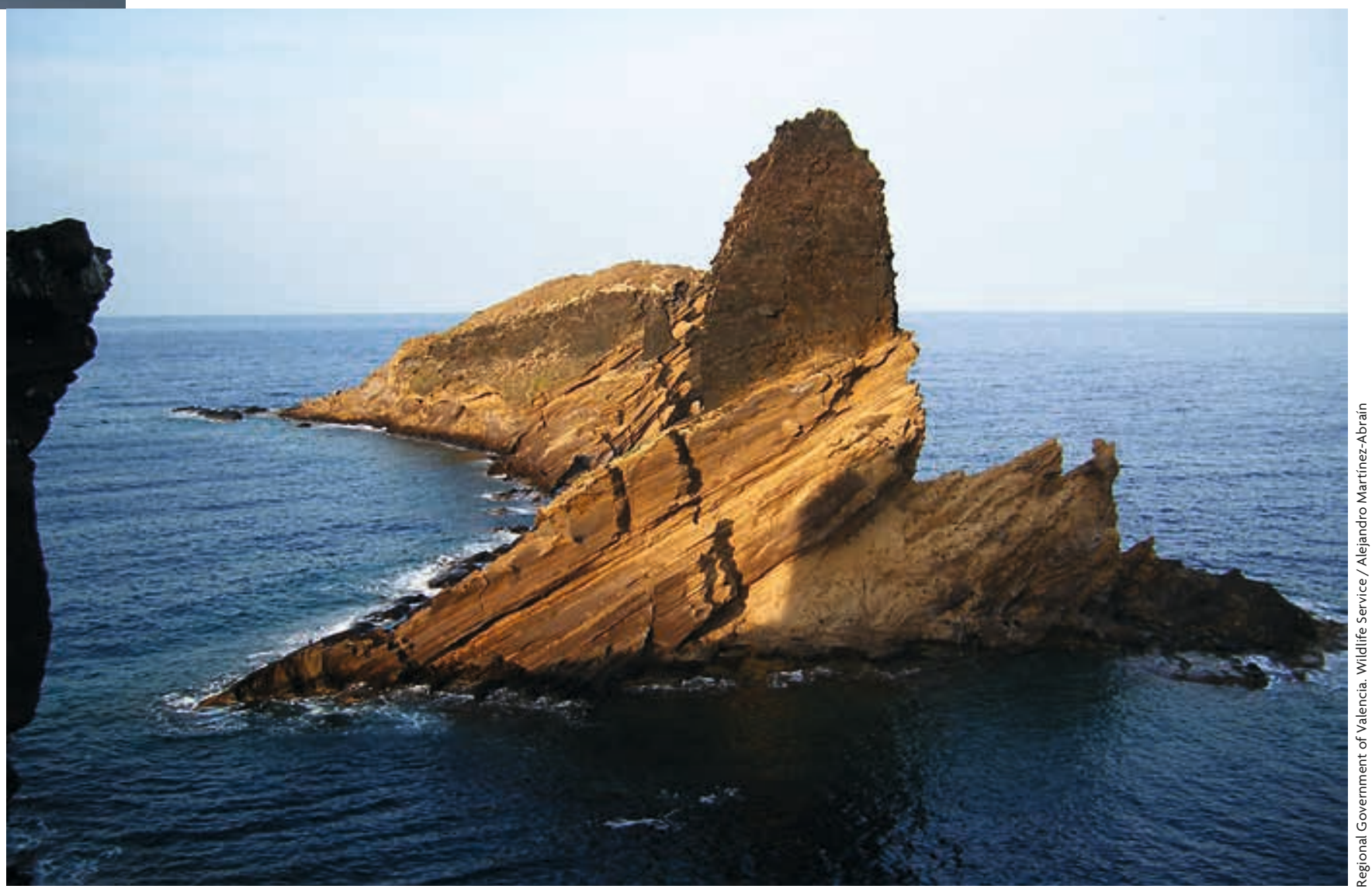

Figure 3. The Audouin's gulls, emblem of the conservation of the Columbretes Islands nature reserve (Spain), were proved to be taking refuge there, rather than being the representative of small Mediterranean islets. As soon as appropriate spaces were provided on the coast, they created large colonies in them and left the islets almost empty. The picture shows a view of the islets Mascarat, Senyoreta and Mancolibre. 
locations along the coast (such as the Ebro river delta) were protected these gulls did not hesitate to start breeding there and these are now some the largest colonies of the species in the Mediterranean (the largest in the world, given that these birds only nest in the Mediterranean). Now they breed in operational salt pans, in harbour docks (in Valencia, Castellón, Tarragona, and Barcelona), and even in industrial areas such as Barcelona's Zona Franca. All they need is some peace and quiet and the availability of food - which is guaranteed in the harbour's surroundings. In other words, zero frailty.

Roughly speaking, we have reached the conclusion that we can classify species into three large groups, depending on the extent of human influence over their habitat choice. A species might be found in its original habitat (equivalent to the habitat where they evolved), in a refuge (in suboptimal natural environments), or in substitution habitats - i.e., in environments created by humans which end up replacing the original habitats (Martínez-Abraín \& Galán, 2018; Martínez-Abraín \& Jiménez, 2016). Seagulls who breed in salt pans are an example of the latter, as are herons feeding on rice fields or urban birds that find the replacement for a cliff in a house front or a viaduct. The substitution is sometimes so complete that it is difficult to find some species breeding in their original environments, as is the case with common swifts, swallows, or lesser kestrels. Moreover, from our experience we could say that many species are now in a historical process of abandonment of their refuge, because the anthropic pressures that caused them to retreat there no longer exist or are now much less important (Martínez-Abraín, Jiménez, \& Oro, 2018). In fact, humans often provide the protection which species are actively searching for, especially now that predators are recovering in the wild.

A stroll around the Iberian Peninsula can help us to understand this; if we go to Tierra de Campos (a natural area in the Spanish region of Castile and León), we can find the once elusive winter geese resting in lagoons near villages and by roads. The story is similar for bustards: we can find them resting near roads. Great eagles (golden and Bonelli's eagles) probably breed on cliffs not by choice, but because trees were more vulnerable. Now that their direct persecution by

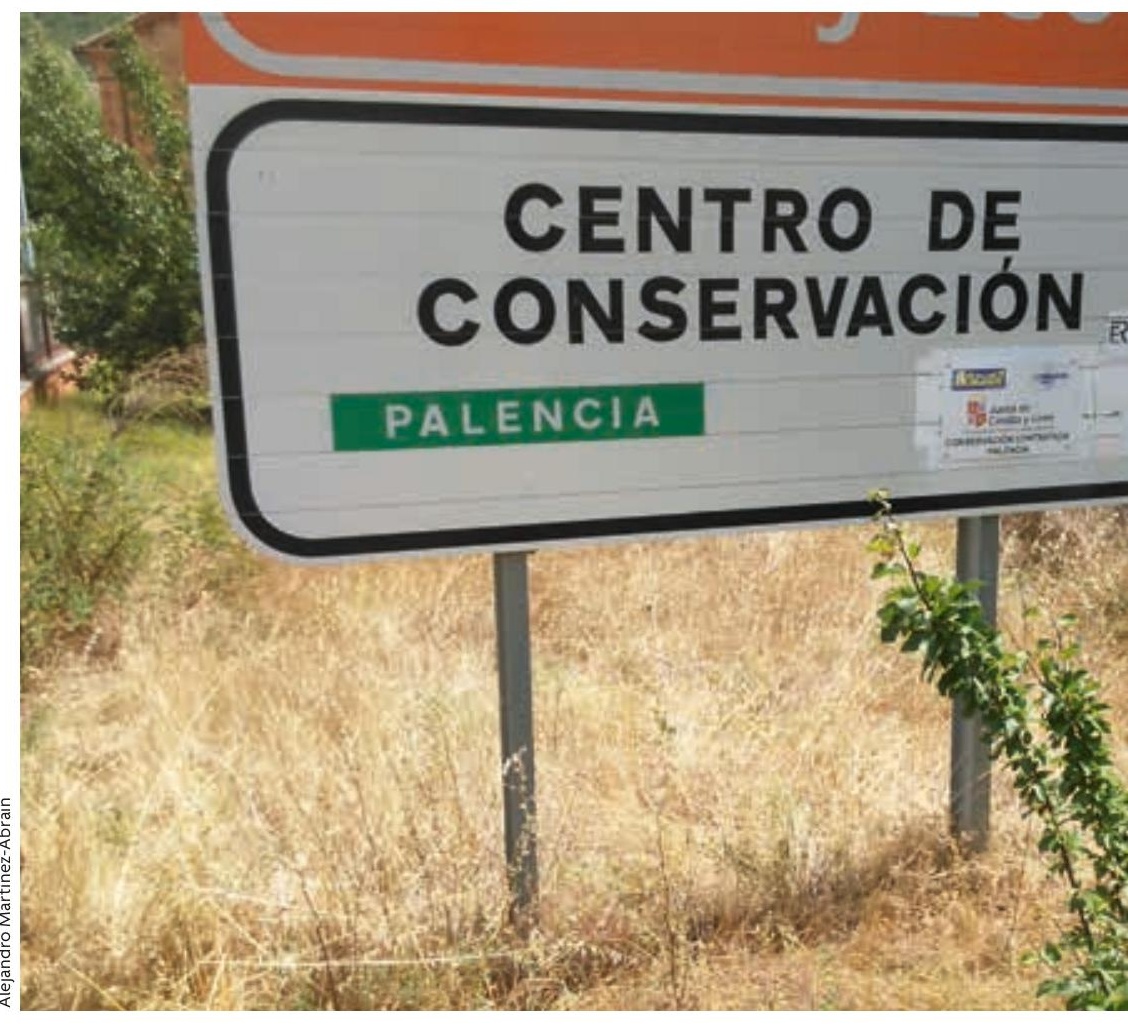

Figure 4. The use of the term conservation for the maintenance of highways sounds quite paradoxical to conservation biologists, who see road infrastructure as a growing concern for wildlife.

humans has decreased, they can be seen breeding in trees more frequently. Something similar is applicable to many plant species we consider vocationally as rupicolous, when in fact, their consumption by herbivores in the past forced them to grow in walls.

Thus, many species are now moving out of what we (mistakenly) considered their typical environments. Not only that, in contrast to the past when only animals that retreated far from the presence of humans could survive, genotypes for species that are bold (i.e., the ones that do not fear us) are now being selected for (Geffroy, Samia, Bess, \& Blumstein, 2015). This type of genetic selection (or emboldenment because of epigenetic reasons of cultural habituation) will lead to the creation of new relationship scenarios between humans and nature. Bears will come closer - although that will not stop them from having claws and fangs; we will find roe deer on our roads more often. We can already see increasing numbers of wild boars, with the associated risk of accidents that their presence entails: until now we were used to driving on roads that crossed landscapes without any wildlife, but this 
